Revista de Estudios Histórico-Jurídicos

[Sección derecho romano]

XXXVII (Valparaíso, Chile, 2015)

[pp. $109-123$ ]

\title{
ACCIONES ADYECTICIAS Y LIMITACIÓN DE RESPONSABILIDAD. UNA HIPÓTESIS EN TORNO A LA JUSTICIA Y LA UTILIDAD EN EL PENSAMIENTO DE ULPIANO*
}

[Actiones Adiecticiae and Limitation of Liability. A Hypothesis on Justice and Usefulness in Ulpiano' Thinking]

\author{
Patricio Lazo** \\ Pontificia Universidad Católica de Valparaíso, Chile
}

\begin{abstract}
RESUMEN
Se examina el pensamiento de Ulpiano a propósito del régimen de responsabilidad contractual al que dan lugar las acciones institoria y exercitoria. El análisis toma por base una hipótesis acerca de la preferencia de los juristas clásicos por la limitación funcional de la responsabilidad y la pone en relación con el pensamiento ulpianeo sobre el mismo aspecto. El análisis se propone, por una parte, indagar en los conceptos de justicia y utilidad empleados por Ulpiano al elogiar el edicto de las acciones exercitoria e institoria; y también pone atención en otras decisiones del mismo jurista que son coincidentes con la tradición jurisprudencial de la limitación funcional de la responsabilidad contractual. La aparente contradicción lleva
\end{abstract}

\begin{abstract}
This is a review of Ulpiano's thinking regarding the regime of contractual responsibility, from which the actiones institoria and exercitoria rise. The analysis is based on a hypothesis that the classical lawyers prefer the functional limitation of liability and relate it to Ulpiano's thinking in that same regard. On one hand, the analysis seeks to investigate the concepts of justice and usefulness used by Ulpiano when he praises the edict of the actiones exercitoria and institoria; and it also pays attention to other decisions, made by Ulpiano, which are consistent with the legal tradition of the functional limitation of the contractual liability. The apparent contradiction entails a hypothesis around Ulpiano's thinking.
\end{abstract}

RECibIDO el 2 de abril y ACEPTADO el 1 de agosto de 2015

* El presente trabajo forma parte del proyecto de investigación FONDECYT No 1120606 : "Limitación de la responsabilidad contractual. Perspectivas histórica y metodológica de un dogma de origen romano" y del proyecto ANILLO-CONICYT código SOC-1111.

** Profesor de derecho romano de la Pontificia Universidad Católica de Valparaíso. Correo electrónico: patricio.lazo@ucv.cl 
a una hipótesis en torno al pensamiento de Ulpiano.

\section{PALABRAS CLAVE}

Actio exercitoria - Actio institoria - Limitación funcional de la responsabilidad - Justicia - Utilidad - Ulpiano.

\section{KEYWORDS}

Actio exercitoria - Actio institoria Functional Limitation of Liability - Justice - Usefulness - Ulpiano.

\section{INTRODUCCIÓN}

No es inusual encontrar en la romanística afirmaciones relativas al hecho de que el pensamiento jurídico del que hacían gala los juristas romanos habría estado orientado por principios. Schulz, uno de los más preclaros ejemplos a este respecto, titula Principios del derecho romano a una de sus más importantes obras, y expresa que por medio de esta noción buscaría "reconocer las ideas fundamentales, en materia de derecho y justicia, de aquellos romanos que se ocupaban de la producción del derecho: de estas ideas han derivado las reglas del derecho romano privado, y son los verdaderos principia, los verdaderos 'veneros' del derecho romano"1.

Las ideas antes expresadas constituyen un marco para una segunda clase de afirmación, como es la de que los juristas romanos, al momento de proponer una solución a un caso, lo hacen buscando lo justo concreto, es decir, aquello que, siendo justo, lo es en primer lugar respecto de dicho problema ${ }^{2}$. Esta afirmación debe ser, en todo caso matizada. Ella no tiene por corolario que el universo de valoraciones de los juristas romanos comience y culmine con la justicia, ya que, en un campo más amplio, abierto a otra clase de normas, la utilidad ocupa también un lugar de importancia, y existe al respecto suficiente evidencia ${ }^{3}$. Navarra expresa que "i giuristi estendono il diritto preesistente, motivano soluzioni che si discostano, per particulari circostanze del caso, da regole di portata generale e che possono essere in aparente contraddizione con il 'sistema" " 4 . Con esta afirmación como garantía, debería descartarse que estas referencias constituyan un recurso retórico de los juristas. Por el contrario, justicia y utilidad serían sólo dos, dentro de un elenco más amplio, de principios de actuación esgrimidos por la jurisprudencia clásica al momento de ofrecer soluciones a problemas concretos. Ellos actuarían en el pensamiento de la jurisprudencia romana al modo de un prius, cuyo contenido se presupone y conforme al cual evalúan la mejor solución a un

${ }^{1}$ Schulz, Fritz, Principios del derecho romano (2a edición, traducción de Manuel Abellán Velasco, Madrid, Civitas, 2000), p. 23.

${ }^{2}$ Sobre la aequitas, VACCA, Letizia, Metodo casistico e sistema prudenziale (Padova, Cedam, 2006), p. 1 ss.

${ }^{3}$ La utilidad es mencionada por GARCÍA GARRIDO, Manuel, Casuismo y jurisprudencia romana ( $3^{\text {a }}$ edición, Madrid, Ediciones Académicas, 2006), p. 25, junto a la bona fides, la aequitas y el officium. SAMPER, Francisco, Derecho Romano (2a edición, Santiago, Ediciones de la Universidad Católica de Chile, 2007), p. 41, señala a la utilidad como principio, junto a los de autoridad, seguridad y equidad.

${ }^{4}$ En relación con la utilitas, véase: NAVARRA, Marialuisa, Ricerche sulla utilitas nel pensiero dei giuristi romani (Torino, Giappichelli, 2002), p. 2. 
problema específico. Desde una perspectiva sistémica, todo ello debería contribuir a que el producto de la interpretación de los prudentes mantuviera un alto grado de coherencia y racionalidad.

En este contexto, la figura de Ulpiano adquiere una importante dimensión. Se trata de uno de aquellos juristas en cuya obra se encuentran con frecuencia referencias a la justicia y la utilidad ${ }^{5}$. Una de las sedes materiae en las que es posible encontrar tales referencias las encontramos a propósito del comentario elaborado por el jurista tardoclásico a los edictos de exercitoria y de institoria actione.

\section{LOS JURISTAS Y EL RÉGIMEN DE ILIMITACIÓN DE LA RESPONSABILIDAD}

Hacia el siglo II a. C. el pretor comienza la creación de una serie de edictos que contienen las acciones que la posteridad conocerá como adyecticias ${ }^{6}$. En el Digesto, los libros 14 y 15 recogen la disciplina de estas acciones: exercitoria (D. 14,1), institoria (D. 14,3), tributoria ${ }^{7}$ (D. 14,4), de peculio (D. 15,1), de in rem verso (D. 15,3) y quod iussu (D. 15,4). Los comentarios, principalmente de Ulpiano, Paulo y Gayo a estas acciones constituyen el núcleo principal de los fragmentos de los que se componen estos títulos, poco más de dos terceras partes del total ${ }^{8}$. Si queremos ampliar las fronteras del universo de literatura jurídica en torno a este tema, debemos también considerar, junto a las obras jurisprudenciales usadas en la composición del Digesto, los comentarios incluidos en las obras institucionales de Gayo y Justiniano.

La creación de estas acciones debió constituir un genuino avance para el desarrollo de las relaciones jurídicas fundadas en el intercambio comercial, sobre todo porque habría mejorado la condición de los contratantes sobre bases más justas. En concreto, estas acciones habrían permitido a los terceros demandar al

${ }^{5}$ En otros juristas, como por ejemplo, Papiniano, esta clase de referencias son también muy abundantes. Sobre Papiniano, véase Ankum, Hans, Papiniano ¿Un jurista oscuro? en Seminarios Complutenses de Derecho Romano (Madrid: Facultad de Derecho de la Universidad Complutense, 1989), I, pp. 33-63; NAVARra, cit. (n. 4), a propósito de las referencias a la utilitas estudia, además de Ulpiano, a Papiniano, Paulo, Macer y Marciano.

${ }^{6}$ SolazzI, Siro, L'età dell actio exercitoria, después en Scritti di diritto romano (Napoli, Jovene, 1963), IV, p. 241 s., conjeturó que la primera de las acciones adyecticias en aparecer fue la exercitoria. Por el contrario, DE LigT, Legal History and Economic History: the Case of the "actiones adiecticiae qualitatis", en Tijdschrift voor Rechtsgeschiedenis (1999), p. 224 ss., postula un orden diferente, comenzando por la actio de peculio y terminando con las acciones exercitoria e institoria.

${ }^{7}$ Conocida y admitida por una parte importante de la romanística es la opinión de VALIÑo, Emilio, Las relaciones básicas de las acciones adyecticias, en Anuario de Historia del Derecho Español, 38 (1968), pp. 377-480, según la cual esta acción no debe incluirse en el elenco de las adyecticias. La opinión contraria es defendida, entre otros, por Miceli, Maria, Sulla struttura formulare delle "actiones adiecticiae qualitatis" (Torino, Giappichelli, 2001), p. 320 ss.; y CERAMI, Pietro - Petrucci, Aldo, Diritto commerciale romano (3a edición, Torino, Giappichelli, 2010), p. 43.

${ }^{8}$ Las rúbricas del Digesto dedicadas a las seis acciones suman un total de 122 fragmentos. De éstos, 43 son extraídos de la obra de Ulpiano, principalmente, comentarios al edicto; 31 corresponden a Paulo, y sólo 10 corresponden al comentario al edicto provincial de Gayo. Los restantes fragmentos corresponden a Africano, Papiniano, Escévola, Juliano, Pomponio, Celso, Javoleno, Floro, Marciano, Nerva, Trifonino y Alfeno. 
pater familias o dominus de aquel hijo o esclavo con los que hubiesen contratado. Tres de estas acciones, a saber, la exercitoria, institoria y la quod iussu habrían permitido a estos terceros hacer efectivos sus créditos en el patrimonio de aquél, de modo de hacerlo responder ilimitadamente por las deudas contraídas por sus dependientes. El conjunto de las acciones adiecticiae qualitatis habría contribuido a la formación de dos clases de actividades económicas: las sujetas a un régimen de responsabilidad ilimitada, relacionadas con las tres acciones ya mencionadas y aquellas sujetas a uno de responsabilidad limitada, relacionada con las acciones de peculio, de in rem verso y tributoria, cuyo vértice era la formación de un peculio por parte del potestad habiente. ${ }^{9}$

En un trabajo dedicado al régimen de limitación de la responsabilidad, Johnston postula una interesante tesis sobre el sentido que habría finalmente adoptado la interpretación jurisprudencial en punto a la responsabilidad ilimitada, específicamente aquella a la que daban lugar las acciones exercitoria e institoria ${ }^{10}$. Según este autor, los juristas romanos, al desarrollar el régimen de responsabilidad de dichas acciones, habrían ido progresivamente restringiendo los supuestos de ilimitación a los que, potencialmente, el edicto habría dado lugar. Y ello tendría su causa que los juristas clásicos habrían asumido con cierta reserva la significativa atenuación que estas acciones suponían del antiguo principio del derecho civil, según el cual el pater familias o dominus no respondía de las obligaciones contraídas por sus dependientes. Sugiere así que, de forma paralela al régimen de responsabilidad financieramente limitada, los juristas habrían desarrollado un régimen de limitación funcional de la responsabilidad, cuyo efecto se encontraría en la restricción de los supuestos en los cuales se hacía efectiva aquella sin limitación ${ }^{11}$. Según Johnston: "it was important that the departure from the well-established rule be kept within strict bounds, and that the creditor be able to have recourse against the principal only when he had done all that he reasonably could do to satisfy himself that the loan was being made for a purpose necessary for the principal's business"12.

Esta hipótesis es conveniente confrontarla no sólo con los testimonios de los juristas altoclásicos, sino también con la de un significativo jurista tardoclásico: Ulpiano. La razón es muy simple: como veremos, el pensamiento de nuestro jurista, aunque no pueda apartarse de la influencia de juristas clásicos -lo que reforzaría la tesis de Johnston- demuestra un alto grado de independencia cuando decide elogiar la creación de los edictos de institoria y exercitoria actione. Ellos tienen una gran significación, puesto que expresan la convicción de que las modificaciones pretorias apuntan en dirección a las exigencias del intercambio comercial ${ }^{13}$. Además, predomina en estos elogios cierta idea de la justicia, en conjunto con la valoración de la utilidad, lo que mueve a preguntarse cuáles podrían ser las dimensiones de

${ }^{9}$ Serrao, Feliciano, Impresa e responsabilità a Roma nell età commerciale (Pisa, Pacini, 1989), pp. 24 ss.

${ }^{10}$ Johnston, David, Limiting Liability: Roman Law and the Civil Law Tradition, en Chicago-Kent Law Review, 70 (1994), p. 1515-1538.

${ }^{11}$ JOHNSTON, cit. (n. 10), p. 1517.

${ }^{12}$ Ibíd., p. 1521.

${ }^{13}$ Navarra, cit. (n. 4), p. 149. 
la justicia que Ulpiano quiere poner de relieve. Podríamos aún expresarlo en otros términos: qué concepto de la justicia es el que subyace a la opinión de Ulpiano. En lo que sigue me propongo examinar cómo en el pensamiento de nuestro jurista se observa la confluencia entre dos tendencias que, en algún caso, se mostrarán como contradictorias: de una parte, la tradición jurisprudencial de la que es tributario $y$, por otra, su propia visión de la justicia en las relaciones comerciales, lo que no impide la elaboración de un sistema de reglas altamente coherente.

\section{LAS DIMENSIONES DE LO ÚTIL Y LO JUSTO EN EL PENSAMIENTO ULPIANEO}

D. 14,1,1pr., sobre la actio exercitoria, reproduce un fragmento de Ulpiano del siguiente tenor: "Utilitatem huius edicti patere nemo est qui ignoret. nam cum interdum ignari, cuius sint condicionis vel quales, cum magistris propter navigandi necessitatem contrahamus, aequum fuit eum, qui magistrum navi imposuit, teneri, ut tenetur, qui institorem tabernae vel negotio praeposuit, cum sit maior necessitas contrahendi cum magistro quam institore" rell. ${ }^{14}$. En un segundo texto, referido esta vez a la actio institoria, D. 14,3,1, nuestro jurista señala: "Aequum praetori visum est, sicut commoda sentimus ex actu institorum, ita etiam obligari nos ex contractibus ipsorum et conveniri" rell.” ${ }^{15}$. Así, Ulpiano sostiene que el primero de los edictos tiene una "manifiesta utilidad", mientras que el segundo de ellos habría surgido por haber parecido "justo" al pretor conceder esta acción (institoria).

La elogiosa opinión de Ulpiano respecto del edicto no es, desde luego, novedosa. Casi cien años antes que él, Gayo había expresado similar idea en términos aún más efusivos: a propósito de la responsabilidad in solidum que ambas acciones permitían hacer efectiva, expresa en Gai. 4,71 respecto de la exercitoria, que "aequissimum esse uisum est in solidum actionem dari", no así respecto de la institoria, de la que se limita a describir que su fórmula "in solidum est". Las palabras de Gayo tienen una especial relevancia, ya que ellas harían radicar la justicia de la acción creada no sólo en la extensión de la legitimación pasiva -que podríamos suponer que también valora- sino en el hecho de que ésta sea in solidum, es decir, ilimitada ${ }^{16}$.

\footnotetext{
14 "Nadie puede ignorar la manifiesta utilidad de este edicto: como por las exigencias del tráfico marítimo contamos con patrones de nave, ignorando a veces su condición y cualidades, era justo que el que nombró patrón para la nave quedara obligado, como se obliga el que puso al frente de un comercio o negocio a un factor" rell. Petrucci, Aldo, Per una storia della protezione dei contraenti con gli imprenditori (Torino, Giappichelli, 2012), I, p. 56, destaca que la utilidad del edicto parecía evidente a Ulpiano, desde el momento que era justo que quienes habían celebrado un contrato, por necesidades de la navegación, con un patrón de nave, podían hacer valer la responsabilidad de quien lo había 'prepuesto', en cuanto le había sido imposible informarse sobre el status del comandante mismo.

15 "Le pareció justo al pretor que, así como experimentamos beneficios con los actos de nuestros factores de comercio (institores), así también quedemos obligados y se nos pueda demandar por los contratos celebrados por ellos" rell.

${ }^{16}$ Recientemente, García Garrido, Manuel, Responsabilidad "in solidum" en la casuistica de la "actio exercitoria", en Russo RuggerI, Carmela (editora), Studi in onore di Antonino Metro (Milano, Giuffrè, 2010), III, p. 1, ha discutido, que la expresión "in solidum eum teneri"
} 
Volviendo nuevamente a Ulpiano, debemos observar que el elogio de la utilidad aparece conectado con el de la justicia, al menos en cuanto se refiere a la actio exercitoria ${ }^{17}$. La redacción entrelaza a ambos valores y podríamos conjeturar que las razones que mueven a Ulpiano a poner de relieve tanto una como otra tienen que ver con las características que le son propias a los negocios marítimos. Ulpiano pone de manifiesto que, a diferencia de lo que ocurre con la contratación terrestre, en la marítima las circunstancias que rodean a la contratación pueden impedir conocer las cualidades del naviero ("cum interdum ignari, cuius sint condicionis vel quales, cum magistris propter navigandi necessitatem contrahamus"). Y nada más decir que la utilidad del edicto es, en este sentido, manifiesta, afirma que es justo que quien nombró al patrón de nave quede obligado por los contratos celebrados por éste ("aequum fuit eum, qui magistrum navi imposuit, teneri"). La razón -agrega nuestro jurista- es que no siempre el lugar y el momento en que ocurre la contratación marítima permiten al tercero informarse sobre el patrón de nave. Podemos entender que Ulpiano se refiere a las pocas posibilidades que tiene el tercero de identificar correctamente a su contraparte, de tener alguna idea de su reputación o de su patrimonio; podría, incluso, referirse al hecho de que el tercero no tendría cómo saber si su contraparte es o no dueña de la nave. Luego, Ulpiano pone de relieve problemas relacionados con aquello que modernamente, y a propósito de la contratación en masa, se denomina 'asimetría de la información'. La utilidad del edicto se predicaría, entonces, del hecho de que éste se dirige a resolver los problemas asociados a dicha anomalía, en la medida que ésta opera en perjuicio de los terceros que contratan con el patrón de nave. Podríamos entender, al menos provisionalmente, que el edicto corregiría un cierto estado de cosas, relativo a la deficiente información en perjuicio del tercero, de modo tal que ella vendría a ser compensada con la ilimitación de responsabilidad de aquel que resultase beneficiado con dicha anomalía que rodea al contrato ${ }^{18}$. Tal sería la utilidad del edicto.

Pero Ulpiano también habla, en este mismo fragmento, de justicia. Sostiene que es justo que quien designó al patrón a cargo de la nave quede obligado por los contratos celebrados por éste. Es decir, ahora el centro del argumento ulpianeo

pueda ser traducida siempre y en todo caso como "responder por entero"; en su opinión, esta traducción debería reservarse para el caso en que un naviero o armador responda de las deudas de su patrón; en cambio, si se trata de la demanda a varios navieros, también en razón de la exercitoria, propone la expresión "solidariamente”. Posiblemente Gayo, al describir el régimen de responsabilidad al que da lugar cada una de estas acciones, simplifica demasiado -quizá por razones propedéuticas- la situación y no proporciona una idea más aproximada a la complejidad que el régimen jurídico de estas acciones alcanzó en la jurisprudencia romana.

${ }^{17}$ Véase NaVArRA, cit. (n. 4), p. 150.

${ }^{18}$ Ibíd., p. 150, lo expresa en los siguientes términos: “L'utilitas dell'editto è fatta discendere dall'equitas che ha ispirato l'innovazione pretoria grazie alla quale viene data protezione ad una situazione, quella dei terzi, che non era tutelata dallo ius civile-nel cui sistema nessuno può essere obbligato attraverso un terzo- ma che la necessitas (necessitas navigandi; necessitas contrahendi cum magistro) impone di tutelare”. Esta postura, mirada desde la perspectiva defendida por Johnston, conduce inevitablemente a una contraposición entre la visión de Ulpiano y la de algunos juristas de época clásica alta. 
se dirige a un aspecto vinculado a la legitimación pasiva, el que, por otra parte, se encuentra estrechamente relacionado con el de la asimetría de información ${ }^{19}$.

De esta forma, el elogio de la justicia que hace Ulpiano respecto del edicto de institoria actione tiene también relación un aspecto de la ética mercantil: el equilibrio entre las ganancias y las obligaciones. Ulpiano sostiene, en este punto, que el pretor consideraba justo que quien obtenía beneficios de los actos de sus factores de comercio, también quedase obligado por lo gestionado por estos ("sicut commoda sentimus ex actu institorum, ita etiam obligari nos ex contractibus ipsorum et conveniri"). En este plano, el mismo argumento podría haberse extendido para la actio exercitoria, en cuanto ella también operaría sobre una premisa similar.

En definitiva, este somero examen acerca del elogio a los dos edictos arroja que las dimensiones las cuales apuntan los calificativos de útil y justo que utiliza Ulpiano, serían tres: la superación de la asimetría de información de los contratantes, la alteración de las reglas sobre legitimación pasiva en beneficio de los terceros contratantes y el reforzamiento de la ética de los negocios, en términos de un equilibrio razonable entre ganancia y contraprestación ${ }^{20}$.

Al tenor de lo dicho, aquello que Ulpiano consideraba justo podía consistir, o bien en el establecimiento de la posibilidad de demandar, o bien en la posibilidad de contar con un patrimonio alternativo al cual imputar la responsabilidad por la deuda. En ambos casos, lo más significativo tendría relación con el patrimonio en el cual podía el tercero cobrar sus deudas: el del naviero, quien, desde luego, respondería ilimitadamente. Por ello no resulta difícil relacionar el adjetivo ‘justo’

${ }^{19} \mathrm{Si}$, llegados a este punto, comparamos los elogios de Gayo y Ulpiano, veríamos que el primero señala que la justicia no sólo consiste en hacer responder por las deudas al que nombró al exercitor o al institor, sino hacerlo responder in solidum. Ulpiano, en cambio, aunque piensa que el edicto es justo, lo cree en cuanto admite la extensión de la legitimación pasiva al pater familias o dominus, sin hacer referencia -quizá por ser consecuencia natural- a dicha responsabilidad in solidum. Con todo, es a pesar de ciertas coincidencias, es difícil intentar trazar una tradición argumental entre ambos juristas, lo que hay que atribuir al desconocimiento de la obra gayana por parte de Ulpiano.

${ }^{20}$ En cuanto al problema de la legitimación pasiva en las acciones adyecticias, las conjeturas acerca de la estructura formularia de cualquiera de ellas, y en concreto, de la actio exercitoria, se reducen a dos tesis. De acuerdo con la primera de estas posiciones, que se remonta al trabajo de KELLER, Friedrich Ludwig, Ueber "Litis contestation" und Urtheil nach classischem römischem Recht (Zurich, Geßner, 1827), la estructura formularia de estas acciones tendría como supuesto que a dependientes tales como el esclavo o el hijo se les llegó a reconocer cierta capacidad para obligarse por sí mismos. En un estado tal de cosas, la innovación habría consistido en extender el número de legitimados pasivos a la acción contractual correspondiente, agregando como legitimado pasivo al naviero, todo lo cual se podría llevar adelante por medio de la técnica de la transposición de personas. La segunda posición es sustentada por MiCELI, cit. (n. 7) y ha sido acogida, entre otros, por KASER, Max - KNÜTEL, Rolf, Römisches Privatrecht (20a edición, München, Beck, 2014), p. 292. Para esta autora, hay razones para poner en duda que al momento de crearse las acciones adyecticias -en particular la exercitoria- la jurisprudencia hubiese ya reconocido cierta capacidad jurídica a los dependientes. Para Miceli, la innovación de las acciones adyecticias habría consistido en conferir a los terceros la posibilidad de demandar al naviero por los contratos de su patrón o capitán de nave, lo que hasta ese momento no habría sido posible, dada la vigencia de la regla según la cual los dependientes no podían obligar al pater familias o dominus. 
que emplea Ulpiano con este hecho. La justicia consistiría, por consiguiente, en el reforzamiento de la posición del tercero de cara a las posibilidades de éxito de su acción. Y en este sentido, el problema de la justicia traduciría una posición ético-jurídica: el del equilibrio ambos contratantes. De acuerdo con Ulpiano este problema sería idéntico a propósito de los contratos celebrados con factores de comercio. Así, la misma razón operaría a propósito de las acciones institoria y exercitoria: sería justo que quien obtiene beneficios de los actos de sus factores de comercio, quedase obligado por los actos de éstos ("sicut commoda sentimus ex actu institorum, ita etiam obligari nos ex contractibus ipsorum et conveniri"). La justicia, por lo tanto, podría predicarse de ambos edictos en cuanto merced a ellos se remediaría un importante problema: que el ius civile no proveía a los acreedores del hijo o del esclavo -cada cual en su rol de patrón de nave o factor de comercio- de mecanismos que les permitieran hacer valer sus créditos en el patrimonio del pater familias.

\section{IV. “Aequitas" y “UTilitas” EN DECisiones Ulpianeas}

Examinemos, a continuación, la forma en que algunas decisiones ulpianeas a propósito de estas acciones ponen en juego las nociones de justicia y utilidad.

En un caso el problema se plantea a propósito del nombramiento de un patrón de nave por parte de otro patrón de nave y la decisión de si se concede o no la acción depende, en parte importante de cómo se elija interpretar los términos del edicto. Por lo mismo, resulta interesante examinar cómo, en este contexto, el recurso a la utilidad proporciona un refuerzo a una determinada opción hermenéutica. D. 14,1,1,5 (Ulp., 28 ed.): "Magistrum autem accipimus non solum, quem exercitor praeposuit, sed et eum, quem magister: et hoc consultus Iulianus in ignorante exercitore respondit: ceterum si scit et passus est eum in nave magisterio fungi, ipse eum imposuisse videtur. quae sententia mihi videtur probabilis: omnia enim facta magistri debeo praestare qui eum praeposui, alioquin contrahentes decipientur: et facilius hoc in magistro quam institore admittendum propter utilitatem. quid tamen si sic magistrum praeposuit, ne alium ei liceret praeponere? an adhuc Iuliani sententiam admittimus, videndum est: finge enim et nominatim eum prohibuisse, ne Titio magistro utaris. dicendum tamen erit eo usque producendam utilitatem navigantium" 21 .

21 "Entendemos por patrón no sólo a aquel que ha sido designado por el naviero, sino también que lo ha sido por el patrón: esto respondió Juliano, consultado sobre el naviero que ignoraba esto <la designación de nuevo patrón por parte del patrón designado por el naviero $>$. Pero si lo sabe y consintió en que aquel haga de patrón en la nave, se estima que lo ha designado él mismo, opinión que me parece acertada, porque de todos los actos del patrón debe responder aquél que lo designó, porque de otra forma quienes contrataren con él serían engañados. Sin duda esto se ha de admitir con mayor razón a propósito del patrón de nave que del factor de comercio, por mor de la utilidad. Pero, ¿qué ocurre si se designó un patrón de forma tal que no le fuese lícito designar a otro? Habrá que ver si admitimos hasta este punto la opinión de Juliano. Por ejemplo, si expresamente se le prohibió “no te valgas de Ticio como patrón”. Sin embargo, se ha de admitir extender <el fundamento de> la utilidad de los navegantes incluso a este punto". MiCELI, cit. (n. 7) n. 32, pp. 203 s., piensa que el texto debió ser originalmente más extenso; más aún, postula que la parte final del fragmento podría no corresponder al original de 
El caso es resuelto primeramente por Juliano. El fragmento hace referencia a dos supuestos posibles, de los cuales Juliano aborda uno y Ulpiano otro. Ello permitiría conjeturar dos cosas: la primera, que la respuesta de Juliano se habría constituido en dominante; la segunda, que el supuesto que trata directamente Ulpiano no debió haberlo sido antes y, por consiguiente, sería una solución que debiera atribuirse directamente a nuestro jurista tardoclásico.

El problema que se plantea a Juliano se refiere a la validez del nombramiento de un capitán o patrón de nave por parte de otro capitán. Hay dos variantes: la primera es que tal nombramiento se haga con conocimiento del naviero, y la segunda, como es obvio, con que se haga sin su conocimiento. Contra lo que podría esperarse, el caso viene resuelto a partir de la segunda de estas variantes. Juliano comienza por hacerse cargo del problema de que el naviero no esté en conocimiento de la designación de un segundo capitán, hecha por el primero. $\mathrm{Su}$ aproximación al problema es la de la definición de los términos, concretamente el de magister navis. En su opinión, cuando el edicto habla de magister navis (patrón o capitán de nave) hace referencia a todo aquel que sea nombrado en tal función, incluso si lo es por parte de otro así designado y sin conocimiento del naviero. Por consiguiente, la decisión de Juliano no llega a forzar los términos del edicto, sino que les da una interpretación que impide, en la práctica, la defraudación de los terceros. Por consiguiente, frente a este recurso definitorio de uno de los términos en juego, carecería de relevancia el hecho de que el naviero no concurriese directamente a dicho nombramiento, e incluso que supiese de él. Como es previsible, el segundo problema del que se hace cargo es más sencillo de resolver, ya que ahora se tratará de saber si el exercitor queda igualmente legitimado pasivamente a la acción en caso de tratarse de un patrón de nave nombrado por otro, pero con su consentimiento. Para Juliano, este supuesto equivale a que el segundo patrón hubiese sino nombrado por él mismo. En definitiva, se concede acción contra el naviero por los actos celebrados por el segundo patrón, haya o no sido nombrado por el naviero, y con independencia que, en caso de no haberlo sido, haya desconocido la situación.

Ulpiano, como parecería previsible, se manifiesta de acuerdo con la opinión de Juliano, sin matices. De hecho, la respuesta de este último guarda perfecta coherencia con la defensa de la justicia que, como hemos visto, hace Ulpiano de los edictos, a propósito de la legitimación pasiva. Ello mueve a Ulpiano a ir más allá para afirmar, a continuación, que por todos los actos del patrón debe responder el que lo nombró ("omnia enim facta magistri debeo praestare qui eum praeposui”) y que el fundamento para que ello sea así es porque, de otro modo, los contratantes serían engañados ("alioquin contrahentes decipientur"). Al sostener esto, Ulpiano vincula la regla de la responsabilidad del naviero por los actos del patrón a la evitación del fraude a los acreedores.

Son conocidos los instrumentos que en el derecho romano se concedieron

Ulpiano, ni siquiera en su aspecto sustancial. Defiende, en cambio, su genuinidad sustancial, PETRUCCI, cit. (n. 14), pp. 68 s, a juicio del cual, especialmente la última parte del fragmento sería coherente con una persistente interdicción, por parte de la jurisprudencia, de la defraudación de la confianza de los terceros, convertida en ratio de varias decisiones. 
ante supuestos de defraudación de los acreedores, el más significativo de los cuales sería el interdicto fraudatorio ${ }^{22}$. El argumento de Ulpiano, sin embargo, no llega tan lejos; más aún, pareciera que su alegato se dirige más bien a situar su respuesta en el contexto de la ética mercantil y es ahí que lo resuelto por Ulpiano guarda coherencia con lo afirmado en D. 14,1,1 pr. Aún más, recurre al principio de la utilidad para sostener su posición, afirmando que esta solución se ha de admitir por causa de la utilidad, tanto en los negocios marítimos como en los terrestres, pero aún más en éstos ("et facilius hoc in magistro quam institore admittendum propter utilitatem").

Existe todavía otro supuesto en el fragmento, que no se encontraba en el responsum de Juliano y que Upiano aborda: ¿qué debería decidirse en el caso de que, al nombrar al primer patrón el naviero haya prohibido expresamente la facultad de nombrar un segundo patrón? En este punto Ulpiano se pregunta si aún es posible valerse del responsum de Juliano, lo que equivaldría a preguntarse si es aplicable la regla que él mismo extrajo de aquella respuesta. Y responde que incluso hasta este punto se ha de admitir la utilidad de los navegantes ("dicendum tamen erit, eo usque producendam utilitatem navigantium"), lo que supone afirmar que, también en este caso ha de concederse la acción contra el naviero, sin que para ello sea un obstáculo prohibición expresa de éste, en orden al nombramiento del segundo patrón.

El alcance que confiere Ulpiano a la utilidad llega así a un máximo de extensión: la utilidad de los navegantes, es decir, de quienes contratan con el naviero, se superpondría a la prohibición inicial del naviero y mantendría a salvo la regla de su legitimación pasiva a la acción por los actos de su capitán. Aunque el naviero exprese claramente su decisión de no permitir el nombramiento de patrones sucesivos, no podrá eximirse de responder por los actos del segundo patrón.

Las diferencias son importantes: Juliano mantiene todavía un cierto equilibrio entre voluntad del empresario individual y la utilidad de los terceros contratantes, y hace responder a aquel en los supuestos de autorización, o bien, ignorancia del nombramiento, pero no extiende la regla a casos de prohibición de nombramiento. Este límite, en cambio, es sobrepasado por la doctrina de Ulpiano, quien concede la acción incluso en tal caso, fundado en la utilidad de los terceros.

Llegados a este punto, dos posibilidades se presentan en el horizonte: la primera, intentar comprender la decisión de Ulpiano suponiendo que el caso tenía otros elementos que no quedaron registrados en la compilación. Podría, por ejemplo, conjeturarse que en el supuesto al que se refiere Ulpiano, el tercero desconocía la prohibición, o bien que ésta pudiese ser posterior a la praepositio. Sin embargo, estas conjeturas no tendrían suficiente base de sustento, al menos, textual. La posibilidad que queda consistiría en ver en esta decisión de Ulpiano un alto grado de autonomía respecto de la tradición jurisprudencial de la que nuestro jurista forma parte, al punto de hacer prevalecer la utilidad por sobre la facultad del empresario de organizar su actividad con decisiones que incluyen

${ }^{22}$ Véase ORs, Xavier d', El interdicto fraudatorio en el derecho romano clásico (Roma - Madrid, Consejo Superior de Investigaciones Científicas, 1976). 
prohibiciones, terminando, así, por disolver cualquier posibilidad de resguardo en este sentido. Ésta es, a mi juicio, la conjetura posible: destacar en el pensamiento ulpianeo marcados rasgos de autonomía y de prevalencia de criterios basados en la ética mercantil.

\section{ULPIANO Y LA LIMITACIÓN FUNCIONAL DE LA RESPONSABILIDAD}

El pensamiento de Ulpiano es, con todo, más complejo. Como ya hemos apuntado, en él no sólo destaca una importante independencia de criterio, sino que convive todo ello con un rasgo muy característico, como lo es ser parte de una tradición jurisprudencial, con la consecuencia obvia de que sus respuestas tiendan a mantenerse en los límites de ella. La valoración que hace Ulpiano de los edictos de las acciones exercitoria e institoria convive, de esta forma, con la actitud de quien se reconoce también parte de una cierta corriente de pensamiento. Precisamente, como parte de esa tradición, nuestro jurista no puede menos que hacer suyos ciertos desarrollos dogmáticos, uno de los cuales es la delimitación de una cierta esfera de decisiones que ponen al pater o dominus fuera del alcance de las acciones de los edictos de marras. En los supuestos que se describen a continuación, la praepositio, en sentido contrario a lo que hemos examinado antes, juega un rol determinante a la hora de impedir una agravación de la responsabilidad contractual del naviero y se constituye, ahora sí, como un límite difícilmente franqueable.

a) D. 14,1,1,12 (Ulp., 28 ed.): "Igitur praepositio certam legem dat contrahentibus. quare si eum praeposuit navi ad hoc solum, ut vecturas exigat, non ut locet ( quod forte ipse locaverat), non tenebitur exercitor, si magister locaverit: vel si ad locandum tantum, non ad exigendum, idem erit dicendum: aut si ad hoc, ut vectoribus locet, non ut mercibus navem praestet, vel contra, modum egressus non obligabit exercitorem: sed et si ut certis mercibus eam locet, praepositus est, puta legumini, cannabae, ille marmoribus vel alia materia locavit, dicendum erit non teneri. quaedam enim naves onerariae, quaedam (ut ipsi dicunt) epibatygoi sunt: et plerosque mandare scio, ne vectores recipiant, et sic, ut certa regione et certo mari negotietur, ut ecce sunt naves, quae Brundisium a Cassiopa vel a Dyrrachio vectores traiciunt ad onera inhabiles, item quaedam fluvii capaces ad mare non suficientes" 23 . En este extenso pasaje Ulpiano explica por medio de cada uno de los ejemplos el hecho de que

${ }^{23}$ "Así, pues, el nombramiento de patrón proporciona a los contratantes una cierta regla. Por lo cual, si le puso al frente de una nave sólo para que cobre los fletes y no para que dé en arrendamiento (quizá porque él mismo naviero había arrendado), no quedará obligado el naviero si el patrón hubiese arrendado, y si sólo le encargó de arrendar y no de cobrar los fletes, debe decirse lo mismo. Si lo nombró para que contrate el pasaje con los viajeros, pero no para que transporte mercancías en la nave, o viceversa, no obligará al naviero si se excede de sus atribuciones. Si fue nombrado para que arriende la nave para transportar ciertas mercancías, por ejemplo, legumbres o cáñamos, y él la arrendó apara transportar mármoles u otros materiales, se ha de decir que no queda obligado; pues ciertas naves son para mercancías y otras admiten pasajeros (como dice la gente de mar en griego: epibategoi), y sé que los más encargan que no reciban pasajeros, o con la limitación de que contraten con ellos sólo en cierta región o en cierto mar, como por ejemplo, hay naves que de Casiopa o de Dirrachio transportan pasajeros a Brindis, no siendo idóneas <allí> para la carga, y también algunas sirven para el río, no siendo idóneas para el mar”. He 
el naviero sólo podrá ser demandado por la acción exercitoria, cuando se trate de aquellos negocios jurídicos para los cuales, de modo específico, hubiese designado al patrón o capitán de nave.

Me parece significativo que ya en el comienzo del fragmento Ulpiano haga una referencia concreta a un aspecto de la superación de la asimetría de la información, al afirmar que la designación (praepositio) da una regla cierta a los contratantes, es decir a los terceros (“certam legem dat contrahentibus"). Desde luego, se trata de una afirmación inicial, pero que sirve para intuir la valoración que hace Ulpiano del tránsito desde una situación de incertidumbre a la contraria: al contar con una praepositio la certa lex (aquí traducida por 'regla cierta') supone un punto de partida valioso para un tipo de contratación que, como la marítima, probablemente dejaba aspectos librados a cierto grado de indeterminación o incertidumbre ${ }^{24}$. Después de esta frase el fragmento ulpianeo proporciona una serie de ejemplos que sirven para justificar que la responsabilidad del naviero no se ve afectada a causa de actos de su magister navis que exceden las atribuciones conferidas en la praepositio ("modum egressus non obligabit exercitorem").

¿Cómo explicar el elogio del edicto precisamente porque él permite reparar la situación de desequilibrio provocada por la asimetría de información? Quizá la respuesta se encuentre en el hecho de que, precisamente, al proporcionar esta regla cierta una base compartida de información, ella equilibra la concurrencia, en el mismo contrato, de un régimen de responsabilidad ilimitada, que operaría a modo de regla general, y uno responsabilidad funcionalmente limitada, como la que se esboza en el caso del exceso de atribuciones, respecto del naviero.

b) D. 14,1,1,13-14 (Ulp., 28 ed.): "Si plures sint magistri non divisis officiis, quodcumque cum uno gestum erit, obligabit exercitorem: si divisis, ut alter locando, alter exigendo, pro cuiusque officio obligabitur exercitor. Sed et si sic praeposuit, ut plerique plerumque faciunt, ne alter sine altero quid gerat, qui contraxit cum uno sibi imputabit" ${ }^{25}$. El fragmento contiene un supuesto de pluralidad de patrones, en el cual el problema consiste en determinar cómo responde el naviero ante las gestiones de varios patrones. El análisis de Ulpiano contempla dos variantes. La primera de ellas es que el naviero no haya realizado división de funciones alguna. De ser así, el tercero que hubiese contratado con cualquiera de los patrones de nave dispondría de acción contra el naviero para exigir su responsabilidad por el negocio celebrado. Es decir, se trata de un supuesto en el cual el régimen de

seguido la traducción de D’Ors, Álvaro y otros, Digesto de Justiniano (Pamplona, EUNSA, 1968). Salvo que se indique otra cosa, los textos traducidos tienen esa procedencia.

${ }^{24}$ Petrucci, cit. (n. 14), p. 61, ofrece para la expresión certam legem la traducción de 'condiciones contractuales' y resalta que "si tratta di un principio de carattere generale da intendersi nel senso che la preposizione deve offrire ai terzi contraenti requisiti di certezza circa i poteri del magister stesso e circa eventuali 'condizioni generali' da rispettare nella contrattazione con lui”. Véase también Cerami - Petrucci, cit. (n. 7), p. 226.

25 "Si fueran varios los patrones y no hubiese división de funciones, cualquier negocio que se hubiese contratado con uno de ellos obligará al naviero; si hubo división de funciones, uno para arrendar y otro para cobrar, el naviero se obligará con arreglo a la función de cada uno. (14) Pero si los nombró de este modo, como hacen muchas veces, que uno no gestione sin el otro, aquel que contrató con uno sólo podrá culparse a sí mismo <pues no obliga al naviero>”. 
responsabilidad ilimitada se aplica en toda regla. La segunda variante consiste que el naviero haya dividido las funciones, en cuyo caso responderá sólo por lo que cada patrón haya contratado. De este modo, Ulpiano reserva al supuesto de la falta de división de funciones la legitimación pasiva del naviero; en cambio, en presencia de dicha división de funciones, la situación es la contraria: el naviero no responderá, es decir, no estará legitimado pasivamente a la acción si el tercero no contrató con el capitán circunscribiéndose a la función para la que se le había designado. Todavía más, si existían gestiones o contratos que debían celebrar ambos conjuntamente, Ulpiano sostiene que aquel tercero que hubiese contratado con uno solo, sibi imputabit, es decir, lamentará haberlo hecho, porque ya no podrá ejercitar la acción contra el naviero.

Visto desde otra perspectiva, Ulpiano consagra un cierto régimen de limitación de la responsabilidad, no ya en razón de un patrimonio especial, de la forma de organizar la gestión encomendada a los patrones de nave. Ésta podía adoptar entonces dos formas: o bien distribuía funciones entre los diferentes patrones, estableciendo un ámbito de gestión privativo de cada uno, o bien establecía la exigencia de la actuación conjunta de dos o más patrones tratándose de otra clase de gestiones. Esta forma de organizar la actividad de los patrones implicaría mover el centro de gravedad desde el naviero hacia el acreedor, quien en virtud de su diligencia o falta de ella, podría ver menoscabadas sus posibilidades de demandar exitosamente al naviero

Podríamos incluso ir un poco más allá y sostener que, hubiese o no división de funciones, debía además cumplirse un segundo requisito: que el contrato celebrado tuviese como objeto uno de los negocios para lo cual el o los patrones habían sido nombrados, como el propio Ulpiano se encarga de poner de relieve en D.14,1,1,7 (Ulp., 28 ed.): "Non autem ex omni causa praetor dat in exercitorem actionem, sed eius rei nomine, cuius ibi praepositus fuerit, id est si in eam rem praepositus sit, ut puta si ad onus vehendum locatum sit aut aliquas res emerit utiles naviganti vel si quid reficiendae navis causa contractum vel impensum est vel si quid nautae operarum nomine petent ${ }^{26}$. Se trata de la significativa función que viene a cumplir la determinación del objeto del contrato, pero todo ello es una cuestión que excede los límites de este trabajo.

\section{CONCLUSIONES}

Nuestro examen ha permitido identificar tres dimensiones de la contratación que Ulpiano juzgaba justas o útiles y que subyacían a su elogio, a saber: la información de las partes, la ética de los negocios y la legitimación procesal. Tales dimensiones eran patentes en algunas decisiones de Ulpiano, a propósito de esta materia. Sin embargo, al mismo tiempo ha sido posible constatar cómo en otras

\footnotetext{
26 "No por cualquier causa el pretor da acción contra el naviero, sino solo por razón del negocio que fue encomendado al patrón, es decir, si éste hubiese sido puesto para aquel negocio, como, por ejemplo, si se hubiese arrendado el transporte de mercancías, o si hubiese comprado algunas cosas útiles para la navegación, o si se contrató o se gastó algo para reparar la nave, o si la tripulación pidiera algo por su servicio".
} 
decisiones de Ulpiano, éste admite la posibilidad de limitar funcionalmente la responsabilidad de quien lleva adelante una actividad económica. En mi opinión, ello aporta algunas evidencias a favor de la tesis de Johnston: si los juristas altoclásicos tendieron hacia la extensión de los supuestos de limitación funcional de la responsabilidad, Ulpiano no pudo mantenerse ajeno a esa tradición jurisprudencial. Con todo, su visión de la justicia, tal como se extrae de otros fragmentos examinados, permiten, al mismo tiempo, conjeturar que nuestro jurista guardó cierta distancia crítica, de modo que fue capaz de exhibir cierta autonomía. Ello se refleja en su valoración de los edictos que consagraban las acciones exercitoria e institoria.

De esta forma, el pensamiento ulpianeo reflejaría su cercanía a una tradición jurisprudencial y, al mismo tiempo, un alto grado de autonomía. Se trataría, por consiguiente, de un pensamiento dentro del cual coinciden perspectivas que bien podrían considerarse contrapuestas y que, no obstante ello, no se anulan, sino que se articulan de una manera coherente. De este modo, creo que se pone de manifiesto que una tensión entre tendencias opuestas presentes en el pensamiento del mismo jurista, no tiene por resultado la anulación de ambas sino que, por el contrario, da lugar a un sistema de reglas que no hace más que reflejar la complejidad de la lógica inherente a la concepción jurisprudencial del derecho propia de la época clásica.

\section{BiBLIOGRAFÍA}

Ankum, Hans, Papiniano ¿Un jurista oscuro? en Seminarios Complutenses de Derecho Romano (Madrid, Facultad de Derecho de la Universidad Complutense, 1989), I, pp. 33-63.

Cerami, Pietro - Petrucci, Aldo, Diritto commerciale romano ( $3^{a}$ edición, Torino, Giappichelli, 2010).

De LigT, Luuk, Legal History and Economic History: the Case of the "actiones adiecticiae qualitatis", en Tijdschrift voor Rechtsgeschiedenis, 67 No 3.

García Garrido, Manuel, Casuismo y jurisprudencia romana (Madrid, Ediciones Académicas, 2006).

García Garrido, Manuel, Responsabilidad "in solidum" en la casuística de la "actio exercitoria", en: Russo RuggerI, Carmela (editora), Studi in onore di Antonino Metro (Milano, Giuffrè, 2010), III, pp. 1-10

Johnston, David, Limiting Liability: Roman Law and the Civil Law Tradition, en Chicago-Kent Law Review, 70 (1994).

Kaser, Max - KNÜTel, Rolf, Römisches Privatrecht, (20ª edición, München, Beck, 2014).

KELLER, Friedrich Ludwig, Ueber "Litis contestation" und Urtheil nach classischem römischem Recht (Zurich, Geßner, 1827O).

Miceli, Maria, Sulla struttura formulare delle "actiones adiecticiae qualitatis" (Torino, Giappichelli, 2001).

NAVARRA, Marialuisa, Ricerche sulla "utilitas" nel pensiero dei giuristi romani (Torino, Giappichelli, 2002).

ORs, Xavier d', El interdicto fraudatorio en el derecho romano clásico (Roma - Madrid, Consejo Superior de Investigaciones Científicas, 1976). 
Petrucci, Aldo, Per una storia della protezione dei contraenti con gli imprenditori (Torino, Giappichelli, 2012), I.

SAmper, Francisco, Derecho romano (2a edición, Santiago, Ediciones de la Universidad Católica de Chile, 2007).

Schulz, Fritz, Principios del derecho romano (2a ed., trad. de Manuel Abellán Velasco, Madrid, Civitas, 2000).

Serrao, Feliciano, Impresa e responsabilità a Roma nell età commerciale (Pisa, Pacini, 1989).

Solazzi, Siro, L'età dell actio exercitoria, en Scritti (Napoli, Jovene, 1963), IV.

VACCA, Letizia, Metodo casistico e sistema prudenziale (Padova, Cedam, 2006).

VAlINo, Emilio, Las relaciones básicas de las acciones adyecticias, en Anuario de Historia del Derecho Español, 38 (1968). 
